\title{
Atmospheric Pressure Plasma CVD of Amorphous Hydrogenated Silicon Carbonitride (a-SiCN:H) Films Using Triethylsilane and Nitrogen
}

\author{
Srinivasan Guruvenket,* Steven Andrie, Mark Simon, Kyle W. Johnson, \\ Robert A. Sailer
}

Amorphous hydrogenated silicon carbonitride (a-SiCN:H) thin films are synthesized by atmospheric pressure plasma enhanced chemical vapor (AP-PECVD) deposition using the Surfx Atomflow $^{\mathrm{TM}}$ 250D APPJ source with triethylsilane ( $\mathrm{HSiEt}_{3}, \mathrm{TES}$ ) and nitrogen as the precursor and the reactive gases, respectively. The effect of the substrate temperature $\left(T_{s}\right)$ on the growth characteristics and the properties of a-SiCN:H films was evaluated. The properties of the films were investigated via scanning electron microscopy (SEM), atomic force microscopy (AFM) for surface morphological analyses, Fourier transform infrared spectroscopy (FTIR), and X-ray photoelectron spectroscopy (XPS) for chemical and compositional analyses; spectroscopic ellipsometry for optical properties and thickness determination and nanoindentation to determine the mechanical properties of the a-SiCN:H films. Films deposited at low $T_{\mathrm{s}}$ depict organic like features, while the films deposited at high $T_{\mathrm{s}}$ depict ceramic like features. FTIR and XPS studies reveal that an increases in $T_{\mathrm{s}}$ helps in the elimination of organic moieties and incorporation of nitrogen in the film. Films deposited at $T_{\mathrm{s}}$ of $425^{\circ} \mathrm{C}$ have an index of refraction $(n)$ of 1.84 and hardness $(H)$ of $14.8 \mathrm{GPa}$. A decrease in the deposition rate between $T_{\mathrm{s}}$ of 25 and $250^{\circ} \mathrm{C}$ and increase in deposition rate between $T_{\mathrm{S}}$ of 250 and $425^{\circ} \mathrm{C}$ indicate that the growth of a-SiCN:H films at lower $T_{\mathrm{s}}$ are surface reaction controlled, while at high temperatures film growth is mass-transport controlled. Based on the experimental results, a potential route for film growth is proposed.

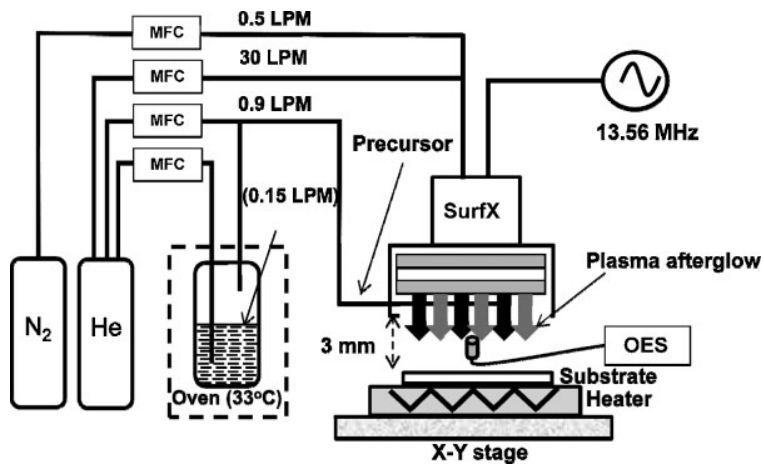

S. Guruvenket, R. A. Sailer

Center for Nanoscale Science and Engineering, North Dakota State University, Research Park Drive, Fargo, North Dakota 58102, USA

Fax: +1 701231 5306; E-mail: guruvenket.srinivasan@ndsu.edu S. Andrie, M. Simon, K. W. Johnson

Department of Mechanical Engineering, North Dakota State

University, 111 Dolve Hall, Fargo, North Dakota 58102, USA

\section{Introduction}

Amorphous thin films of silicon such as silicon nitride (a-SiN:H), silicon carbide (a-SiC:H), silicon carbonitride (a-SiCN:H), etc. find applications as protective coatings, dielectric gate layers in microelectronics applications, and optical coatings such as anti-reflection coatings in solar cells, etc. ${ }^{[1-4]}$ Plasma enhanced chemical vapor deposition 
(PECVD) is a widely used technique to synthesize these coatings, which utilizes hazardous chemicals like silane, ammonia, and/or methane at low pressures. ${ }^{[4]}$ Typical low-pressure direct PECVD (D-PECVD) processes utilize electron-initiated mechanisms to cause fragmentation of the precursor molecules. This is followed by gas phase reactions among the fragmented molecules to form active radicals that lead to film formation on the substrate. In DPECVD, the substrate is immersed in the plasma and undergoes ion bombardment leading to undesired residual stress in the deposited thin films. ${ }^{[5]}$ This residual stress can be minimized by using a remote PECVD (R-PECVD) process, where the precursor reacts with the reactive radicals in the region that is isolated from the energetic ions and electrons. Wrobel and coworkers ${ }^{[6-10]}$ used a R-PECVD process with various metal-organic precursor sources with different gas compositions to form the afore-mentioned Si based thin films at low-pressures.

Facilitation of PECVD processes at atmospheric pressure which make use of non-hazardous chemicals (precursors) will find effectiveness in a continuous manufacturing environment, where rewards are foreseen in terms of higher throughput and lower costs (i.e., capital and operational). In the recent past, there has been an increasing interest in utilizing atmospheric pressure plasma (APP) based surface processing methods for surface activation (cleaning), plasma polymerization and atmospheric pressure PECVD (AP-PECVD).$^{[11-13]}$ Bárdos and Baránková ${ }^{[14]}$ in their recent article summarized some examples of thin film metal oxides, plasma polymers and diamond-like carbon (DLC) materials deposited using AP-PECVD. Interesting observations were made by several researchers that good quality thin films at atmospheric pressure could be synthesized by optimizing the processing conditions (i.e., precursor and reactive gas chemistries, plasma power, substrate temperature, etc). Raballand et al., ${ }^{[15]}$ demonstrated the deposition of $\mathrm{SiO}_{2}$ and $\mathrm{SiOC}$ thin films using organosilanes such as trimethylsilane and hexamethylydisiloxane (HMDSO) by tuning the reactive gas concentration and the plasma power density. The same authors observed $\mathrm{SiO}_{2}$ films free of carbon when the HMDSO flow was balanced with reactive $\mathrm{O}_{2}$ gas. ${ }^{[16]}$ Hopfe and Sheel ${ }^{[17,18]}$ and Hopfe et al., ${ }^{[19]}$ deposited goodquality $\operatorname{SiN}_{x}$ films using a linear extended DC arc reactor with mixtures of $\mathrm{SiH}_{4}, \mathrm{HSi}\left(\mathrm{CH}_{3}\right)_{3}, \mathrm{~N}_{2}$, and $\mathrm{NH}_{3}$ gases. Nowling et al., ${ }^{[20,21]}$ and Ladwig et al., ${ }^{[22]}$ demonstrated the deposition of $\mathrm{SiN}_{x}$ using $\mathrm{He}-\mathrm{SiH}_{4}-\mathrm{N}_{2}$ mixtures and DLC using $\mathrm{He}-\mathrm{CH}_{4}$ mixtures, respectively, using Surfx Atomflow $^{\mathrm{TM}}$ 250D-APPJ. Earlier, we reported the use of AP-PECVD processing to form $\mathrm{SnO}_{x}, \mathrm{In}: \mathrm{SnO}_{x}, \mathrm{ZnO}$, and $\mathrm{Al}: \mathrm{ZnO}$ coatings, where we established that the deposited film's properties strongly depend on the chemistry of the precursors, the reactive gas chemistries and the other processing conditions. ${ }^{[23-25]}$
Despite several reports on AP-PECVD, the interrelationships between the plasma properties, precursor chemistries, growth conditions, and their effect on film properties are not well understood. In this article we report the use of triethylsilane $\left(\mathrm{HSiEt}_{3}\right)$ and nitrogen to form a-SiCN:H thin films at atmospheric pressure using Surfx Atomflow ${ }^{\mathrm{TM}}$ 250D APPJ source. The fundamental processes underlying film growth were elucidated from the thin film's properties; plasma characterization will also be discussed.

\section{Experimental Section}

\subsection{Deposition of a-SiCN:H Coatings}

Thin films of a-SiCN:H were deposited using a Surfx Atomflow ${ }^{\mathrm{TM}}$ 250D APPJ system described elsewhere. ${ }^{[25-27]}$ A schematic representation of the AP-PECVD system and the precursor delivery is shown in Figure 1. $\mathrm{HSiEt}_{3}$, was used as the precursor which is a liquid at standard temperature and pressure (b.p. 117-118 ${ }^{\circ} \mathrm{C}$ ). TES has a significant vapor pressure $\left(P_{\mathrm{v}}=23 \mathrm{Torr}\right.$ at $20^{\circ} \mathrm{C}$, used as received from Gelest, USA). $\mathrm{HSiEt}_{3}$ was delivered to the plasma source from a heated bubbler maintained at $33^{\circ} \mathrm{C}$ (to increase vapor pressure). In order to preclude the precursor condensation, the delivery lines were maintained at $100^{\circ} \mathrm{C}$ and the plasma head was held at $125^{\circ} \mathrm{C}$. Helium and $\mathrm{N}_{2}$ were used as the plasma and reactive gases, respectively, and their flows were maintained at 30 and $0.5 \mathrm{lpm}$, respectively, while the precursor carrier gas (He) flow was kept at $0.15 \mathrm{lpm}$ through the precursor bubbler. The flow path of the precursor, plasma gas and the reactive gas are illustrated in Figure 1. In this investigation plasma power was held a constant at $120 \pm 10 \mathrm{~W}$, while the substrate temperature $\left(T_{\mathrm{s}}\right)$ was varied between the room temperature $(\mathrm{RT}, 25)$ and $425^{\circ} \mathrm{C}$. The substrate to plasma distance was fixed at $3 \mathrm{~mm}$. Crystalline double-side polished intrinsic Si wafers $\left(2.5 \times 2.5 \mathrm{~cm}^{2}\right)$ cleaned with isopropyl alcohol were used as the substrates. Depositions were carried out by moving the heated substrate holder (platen) under the plasma source in a serpentine motion. The serpentine motion parameters (length, width, step size, and velocity) were chosen to produce uniform film deposition across the entire substrate surface. In order

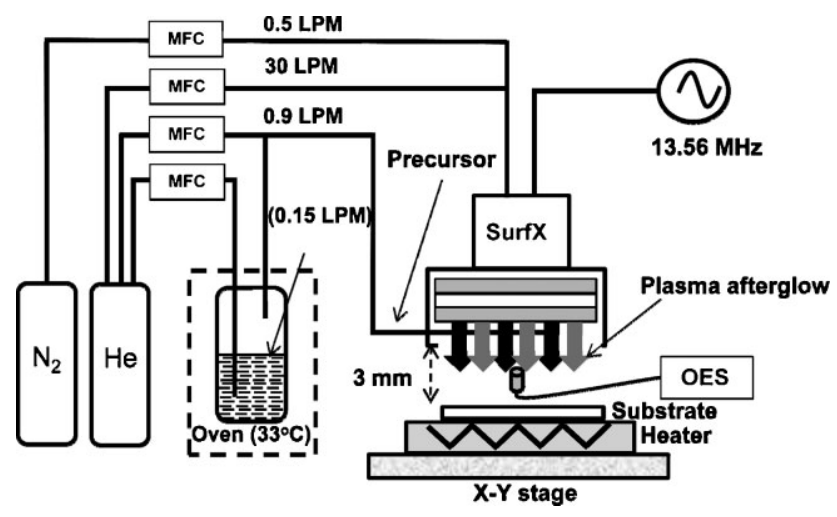

Figure 1. Schematic representation of AP-PECVD system with Surfx ${ }^{\top M} 200$ (Atomflo). 
to preclude oxygen contamination, the plasma source was located inside an inert atmosphere (glove box filled with nitrogen).

\subsection{Plasma and Thin Film Characterization}

Optical emission spectroscopic (OES) analyses were performed using an Ocean Optics SD 2000 spectrophotometer coupled with an optical fiber to characterize the afterglow region of the Surfx $^{\mathrm{TM}} 250 \mathrm{D}$ plasma source as illustrated in Figure 1. The optical fiber was placed along the axis of the plasma source at $\sim 3 \mathrm{~mm}$ to collect the light intensity normal to the electrode. OES spectra were measured between 180 and $890 \mathrm{~nm}$ with a resolution of $0.4 \mathrm{~nm}$.

Surface morphology of the films was investigated using JEOL JSM 7600F high resolution scanning electron microscope (SEM) equipped with a field emission gun. To avoid surface charging, samples were coated with $\sim 10 \mathrm{~nm}$ of conducting layer, while secondary electrons were used to map the surface morphology of the coatings. In order to compliment the SEM analysis and to obtain quantitative details on the surface roughness Atomic force microscopy (AFM) studies were performed using Veeco DI-3100 instrument in tapping mode.

To investigate the chemical (bonding) structure of the films, Fourier transform infrared spectroscopy (FTIR) was performed using a Thermo Scientific Nicolet 8700 instrument, and X-ray photoelectron spectroscopy (XPS) measurements were performed on a Surface Science Instruments (SSX-100) equipped with a monochromatic Al $\mathrm{K} \alpha$ source, a hemispherical sector analyzer (HAS), and a resistive anode detector. The base pressure and pressure during data collection were $10^{-9}$ and $10^{-8}$ Torr, respectively. Survey and high resolution scans were performed to determine the elemental composition and their chemical structure, respectively.

Optical constants of the films were determined using a J. A. Woollam VASE spectroscopic ellipsometer with modeling and data analyses realized using WVASE software package. Ellipsometric $\Psi$ and $\Delta$ data were acquired at three angles of incidence $\left(60^{\circ}, 67^{\circ}\right.$, and $74^{\circ}$ ) over the spectral range $300-780 \mathrm{~nm}$ in steps of $10 \mathrm{~nm}$. Optical constants and the thickness of the films were determined by modeling a thin film on a Si substrate.

Hardness $(H)$ and reduced Young's modulus $\left(E_{\mathrm{r}}\right)$ of the coatings were determined by depth sensitive indentation using a Triboindenter (Hysitron Inc.) system equipped with a Berkovich pyramidal tip. The applied loads ranged between 1 and $5 \mathrm{mN}$. For each sample, $H$ and $E_{\mathrm{r}}$ were obtained from the average of 20 indentations using the method proposed by Oliver and Pharr. ${ }^{[28]}$ Care has been taken in selecting the maximum load to ensure the measurements were performed at within $10 \%$ of the film thickness to avoid the substrate effect.

\section{Results and Discussion}

In this study, the effect of $T_{\mathrm{s}}$ on the properties of a-SiCN:H films were investigated. Films were deposited by varying $T_{\mathrm{s}}$ between 25 and $425^{\circ} \mathrm{C}$, and their microstructural, chemical, optical, and mechanical properties were examined. Experiments depicted no film formation without $\mathrm{N}_{2}$ addition to the plasma gas (He) showing AP-PECVD is a radical initiated process and hence $500 \mathrm{sccm}$ of $\mathrm{N}_{2}$ flow was maintained.

Surface topography and the roughness of the a-SiCN:H films were analyzed via SEM and AFM, respectively. Figure $2 \mathrm{a}$ and $\mathrm{b}$ shows the SEM surface features of the a-SiCH surface deposited at 25 and $425^{\circ} \mathrm{C}$, respectively. It can be observed that the films deposited at $25^{\circ} \mathrm{C}$ show
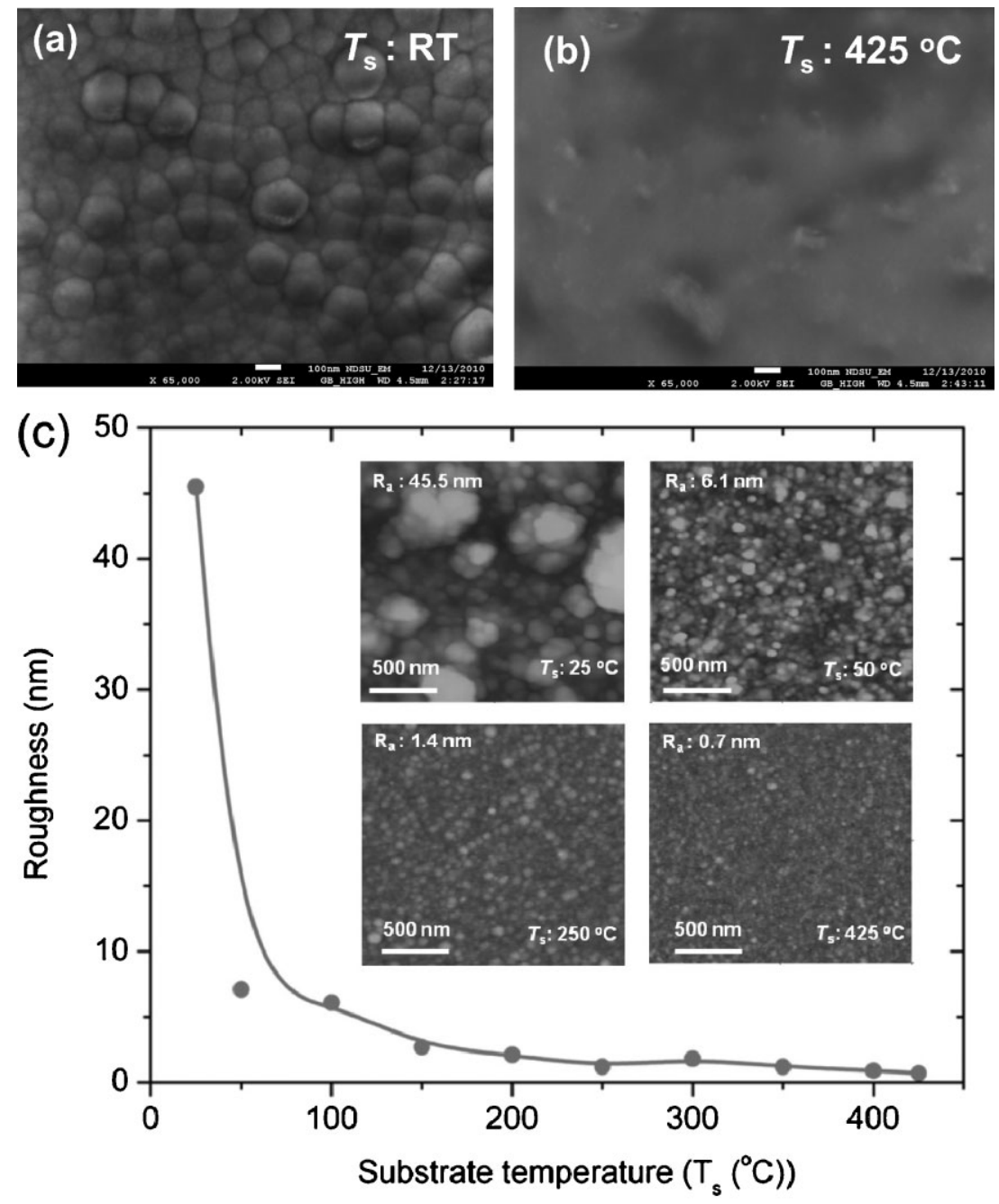

Figure 2. (a) and (b) SEM surface morphology of the a-SiCN:H films deposited at RT and $425^{\circ} \mathrm{C}$, respectively and (c) change in $R_{\mathrm{a}}$ versus $T_{\mathrm{s}}$ (inset: AFM surface topography). 
collections of "globule-like" rough features, while the film deposited at $425^{\circ} \mathrm{C}$ shows no such features. In order to obtain more quantitative roughness values and surface features, AFM measurements were performed and the average surface roughness $\left(R_{\mathrm{a}}\right)$ and surface features as a function of $T_{\mathrm{s}}$ are presented in Figure $2 \mathrm{c}$ and its inset, respectively. As observed in Figure $2 \mathrm{c}$ and its inset, films deposited at $25^{\circ} \mathrm{C}$ show rough, agglomerated, globule-like features with $R_{\mathrm{a}}$ of $45.5 \mathrm{~nm}$. With an increase in the $T_{\mathrm{s}}$, globule-like features could not be observed and a decrease in the $R_{\mathrm{a}}$ from 45.5 to $0.5 \mathrm{~nm}$ (at $T_{\mathrm{s}}: 425^{\circ} \mathrm{C}$ ) was noted. The $R_{\mathrm{a}}$ values observed for films deposited at $T_{\mathrm{s}}>300^{\circ} \mathrm{C}$ are comparable to the $R_{\mathrm{a}}$ observed for $\mathrm{SiN}_{\chi}$ films obtained using PVD, PECVD and CVD techniques. ${ }^{[29-31]}$ High $R_{\mathrm{a}}$ at low $T_{\mathrm{s}}$ and low $R_{\mathrm{a}}$ at high $T_{\mathrm{s}}$ suggest substrate temperatures induce chemical reactions at the growing surface leading to lower roughness. Thin film growth at the low temperatures can be viewed as Volmer-Weber mode (island growth) where the incoming species get absorbed (without any random diffusive jumps) on the substrate leading to porous features as depicted by SEM and AFM morphological studies. While on the other hand, an increase in $T_{\mathrm{s}}$ offers more energy to the incoming adatoms/admolecules as well as decreasing the surface energy (with $1^{\circ} \mathrm{C}$ increase in $T_{\mathrm{s}}, \sim 0.05 \mathrm{~mJ}$ decrease in surface energy is typical) leading to a possible Frank-Vander Merwe (layer by layer) growth mode. ${ }^{[32]}$

Chemical structures of the films were investigated using FTIR spectroscopic analyses which provided important and interesting results. Figure 3 depicts FTIR spectra of the films deposited at $T_{\mathrm{s}}$ from 25 to $425^{\circ} \mathrm{C}$. a-SiCN:H films synthesized at $25-150^{\circ} \mathrm{C}$ depict similar features with absorptions bands at $\sim 1030-1050 \mathrm{~cm}^{-1}$ and $2880-2960 \mathrm{~cm}^{-1}$ corresponding to $\mathrm{Si}-\left(\mathrm{CH}_{2}\right)_{n}-\mathrm{Si}$ or $\mathrm{Si}-\mathrm{O}$, and $\mathrm{CH}_{n}(n=1-3)$, respectively. Weak absorption peaks at $1240,1170,2050-2010$ and

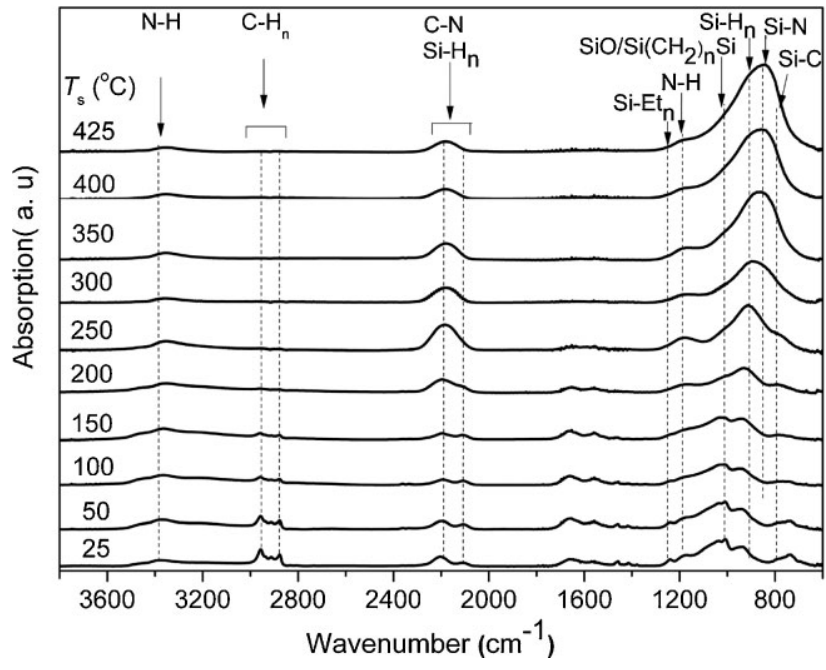

Figure 3. FTIR spectra of a-SiCN:H thin films deposited at $T_{\mathrm{s}}$ from 25 to $425^{\circ} \mathrm{C}$.
$3890 \mathrm{~cm}^{-1}$ corresponding to $\mathrm{Si}-\mathrm{Et}_{n}, \mathrm{Si}-\mathrm{NH}-\mathrm{Si}(\mathrm{C}), \mathrm{Si}-\mathrm{H}_{n}$ $(n=1,2)$, and $\mathrm{N}-\mathrm{H}_{n}$ groups were also observed. ${ }^{[33-36]}$ Films deposited at $200^{\circ} \mathrm{C}$ exhibit similar characteristic absorption peaks except absorption intensity corresponding to $\mathrm{CH}_{n}$ bonds $\left(2880-2960 \mathrm{~cm}^{-1}\right)$ which decreased with a concurrent increase in the $\mathrm{Si}-\mathrm{NH}-\mathrm{Si}(\mathrm{C})$ related group at $1170 \mathrm{~cm}^{-1}$. Films deposited at $T_{\mathrm{s}}$ of $250^{\circ} \mathrm{C}$ exhibited significant changes in the IR spectra with absorptions corresponding to $\mathrm{Si}-\mathrm{H}_{n}$ vibrations at $\sim 915$ and $\sim 2150 \mathrm{~cm}^{-1}$ along with $\mathrm{Si}-\mathrm{C}$ (carbidic) and $\mathrm{Si}-\mathrm{N}$ bonds at $\sim 780$ and $\sim 860 \mathrm{~cm}^{-1}$, respectively. The vibration at $915 \mathrm{~cm}^{-1}$ can also be attributed to the $\mathrm{Si}-\mathrm{CH}_{n}$ bonds. ${ }^{\left[{ }^{[37,38]} \mathrm{A}\right.}$ significant decrease in the intensity of $\mathrm{Si}-\left(\mathrm{CH}_{2}\right)_{n}-\mathrm{Si}$ at $1030 \mathrm{~cm}^{-1}$ and Si-Et $\left(\sim 1250 \mathrm{~cm}^{-1}\right)$ groups was also detected. The broad peak between 2050 and $2300 \mathrm{~cm}^{-1}$ could be due to the combined effect of $\mathrm{Si}-\mathrm{H}_{n}$ (2050$\left.2150 \mathrm{~cm}^{-1}\right)$ and $\mathrm{C}-\mathrm{N}\left(2200 \mathrm{~cm}^{-1}\right)$ bonds, which is supported by the XPS results (presented in a later section). ${ }^{[1,29]}$ Film deposited at $300^{\circ} \mathrm{C}$ exhibited similar characteristic features. At $T_{\mathrm{s}}$ above $350^{\circ} \mathrm{C}$ the films showed a decrease in the absorption corresponding to $\mathrm{Si}-\mathrm{H}_{n}$ vibrations at ( 2 150 and at $915 \mathrm{~cm}^{-1}$ ), with significant peak broadening between 700 and $1100 \mathrm{~cm}^{-1}$. This broad peak at $\sim 920 \mathrm{~cm}^{-1}$ could be attributed to the overlap of many components including $\mathrm{Si}-\mathrm{H}_{n}$ and/or $\mathrm{Si}-\mathrm{CH}_{n}$ at $915-940 \mathrm{~cm}^{-1}$ and $\mathrm{Si}-\mathrm{N}$ at $860 \mathrm{~cm}^{-1}$. With an increase in $T_{\mathrm{s}}$ to 400 and $425^{\circ} \mathrm{C}$, no significant change in the chemical features was noticed except that $\mathrm{Si}-\mathrm{H}_{n}\left(2150 \mathrm{~cm}^{-1}\right)$ became insignificant, while the broad peak centered $\sim 920 \mathrm{~cm}^{-1}$ grew in significance. Based on the decrease in $\mathrm{Si}-\mathrm{H}_{n}$ vibration at $2150 \mathrm{~cm}^{-1}$, it can be concluded that the $\mathrm{Si}-\mathrm{H}_{n}$ peak had little contribution to the broad peak $\left(\sim 920 \mathrm{~cm}^{-1}\right)$, which indicated higher fraction of $\mathrm{Si}-\mathrm{C}$ and $\mathrm{Si}-\mathrm{N}$ bonds with an increase in $T_{\mathrm{s}}$.

These observations imply thermally induced reactions between plasma activated $\mathrm{HSiEt}_{3}$ and the nitrogen species on the substrate surface leading to a-SiCN:H film with different chemical features depending on the $T_{\mathrm{s}}$. A detailed chemical route for the film formation is explained in a later section.

In order to determine the elemental composition and the chemical states of the elements present in the films, XPS studies were performed. Atomic percentage of the elements present in the thin films deposited at 25, 150, 250, 350, and $425^{\circ} \mathrm{C}$ were determined using survey scans and are shown in Table 1. Films deposited at $25^{\circ} \mathrm{C}$ exhibit the highest concentration of oxygen (27.8 at.\%), which decreases gradually with an increase in $T_{\mathrm{s}}$ as depicted in Table 1 . aSiCN:H films deposited below $150^{\circ} \mathrm{C}$ show $21-31$ at.\% of carbon and nitrogen $\geq 14.9$ at.\%. With an increase in $T_{\mathrm{s}}$ to $250^{\circ} \mathrm{C}$ and above, the carbon content in the film gradually decreases, while the nitrogen concentration is increased as depicted in Table 1. a-SiCN:H films deposited at $425^{\circ} \mathrm{C}$ showed 51.9 at.\% of Si, 34.6 at.\% of N, 4.8 at.\% of C, and 8.7 at.\% of $\mathrm{O}$. With an increase in $T_{\mathrm{s}}$ the amount of nitrogen 
Table 1. Elemental composition of a-SiCN:H films.

\begin{tabular}{lrrrr} 
& \multicolumn{4}{c}{ Elemental composition (at.\%) } \\
\cline { 2 - 5 } & $\mathbf{S i}$ & $\mathbf{C}$ & $\mathrm{N}$ & $\mathbf{0}$ \\
\hline 25 & 34.9 & 30.6 & 6.7 & 27.8 \\
150 & 42.6 & 21.2 & 14.9 & 21.3 \\
250 & 43.9 & 5.9 & 33.4 & 16.8 \\
350 & 49.7 & 6.9 & 31.8 & 11.6 \\
425 & 51.9 & 4.8 & 34.6 & 8.7
\end{tabular}

incorporated in the film increased with a concurrent decrease in the carbon concentration. The higher concentration of oxygen present in the films deposited at low $T_{\mathrm{s}}$ can be attributed to the postdeposition reactions between the film and ambient oxygen due to the organic nature of the film. On the other hand the films deposited at higher $T_{\mathrm{s}}$ contained lower oxygen content implying possible oxygen reaction during the film synthesis (oxygen contamination could be from the precursor, gases used, and/or the residual oxygen present in the glove box).

Chemical states of the elements present in the a-SiCN:H films were determined using the $\mathrm{Si} 2 \mathrm{p}, \mathrm{C} 1 \mathrm{~s}, \mathrm{~N} 1 \mathrm{~s}$, and $\mathrm{O} 1 \mathrm{~s}$ core level spectra (depicted in Figure 4). From the Si 2p spectra (Figure $5 a$ ) it can be noted that as $T_{\mathrm{s}}$ increases, the bonding state of Si down shifts from 103 to 101.7 and $100.4 \mathrm{eV}$ corresponding to $\mathrm{Si}-\mathrm{O}$, $\mathrm{Si}-\mathrm{N}$, and $\mathrm{Si}-\mathrm{C}$ bonding states, respectively. ${ }^{[39,40]}$ At $T_{\mathrm{s}}, 350^{\circ} \mathrm{C}$ and above, peak broadening and shift in the peak position towards lower B. E could be observed. Such peak shifts are attributed to the presence of $\mathrm{N}$ and $\mathrm{C}$ complexes attached to the Si bonding site in a-SiCN.${ }^{[41,42]} \mathrm{An}$ increase in $\mathrm{Si}-\mathrm{Si}$ bonds (at $99.9 \mathrm{eV}$ ) was also observed for the films deposited at $T_{\mathrm{s}}>350^{\circ} \mathrm{C}$, which is indicative of a possible detachment of the ethylene group from the parent TES molecule leading to increased $\mathrm{Si}-\mathrm{Si}$ cross-linking.

The $\mathrm{C}$ 1s core level spectra of a-SiCN:H films as the function of $T_{\mathrm{s}}$ is depicted in Figure $4 b$. The $C$ 1s spectra exhibited a predominant presence of $\mathrm{C}=\mathrm{C}$ bonds at $285 \mathrm{eV}$; however with an increase in $T_{\mathrm{s}}$ from 25 to $350^{\circ} \mathrm{C}$, an increase in $\mathrm{C}-\mathrm{Si}$ contribution $(283.3 \mathrm{eV})$ was noticed. Further increase in $T_{\mathrm{s}}$ to $425^{\circ} \mathrm{C}$ showed contributions from $\mathrm{C}-\mathrm{N}$ and $\mathrm{C}=\mathrm{N}$ at 286 and $287 \mathrm{eV}$, respectively, in addition to $\mathrm{C}-\mathrm{Si}$ bonds with a simultaneous peak broadening. ${ }^{[39]}$

The $\mathrm{N}$ 1s spectra illustrates interesting properties; at low $T_{\mathrm{s}}\left(<250^{\circ} \mathrm{C}\right)$ the spectra exhibits the presence of $\mathrm{N}=\mathrm{C}$ $(399.2 \mathrm{eV}$ ) and $\mathrm{N}-\mathrm{O}$ (at $400.3 \mathrm{eV}$ ) bonds that signify nitrogen reaction with carbon in the ethyl group of TES radical and the stray oxygen present in the reactor. With an increase in $T_{\mathrm{s}}>250^{\circ} \mathrm{C}$ a gradual down shift in B. E from 399.2 to $397.3 \mathrm{eV}(\mathrm{N}-\mathrm{Si})$ and peak broadening was observed indicating $\mathrm{N}-\mathrm{Si}$ and $\mathrm{N}-\mathrm{C}$ bond formation with marked decrease in $\mathrm{N}-\mathrm{O}$ contribution. ${ }^{[39,41,42]}$ This indicated the
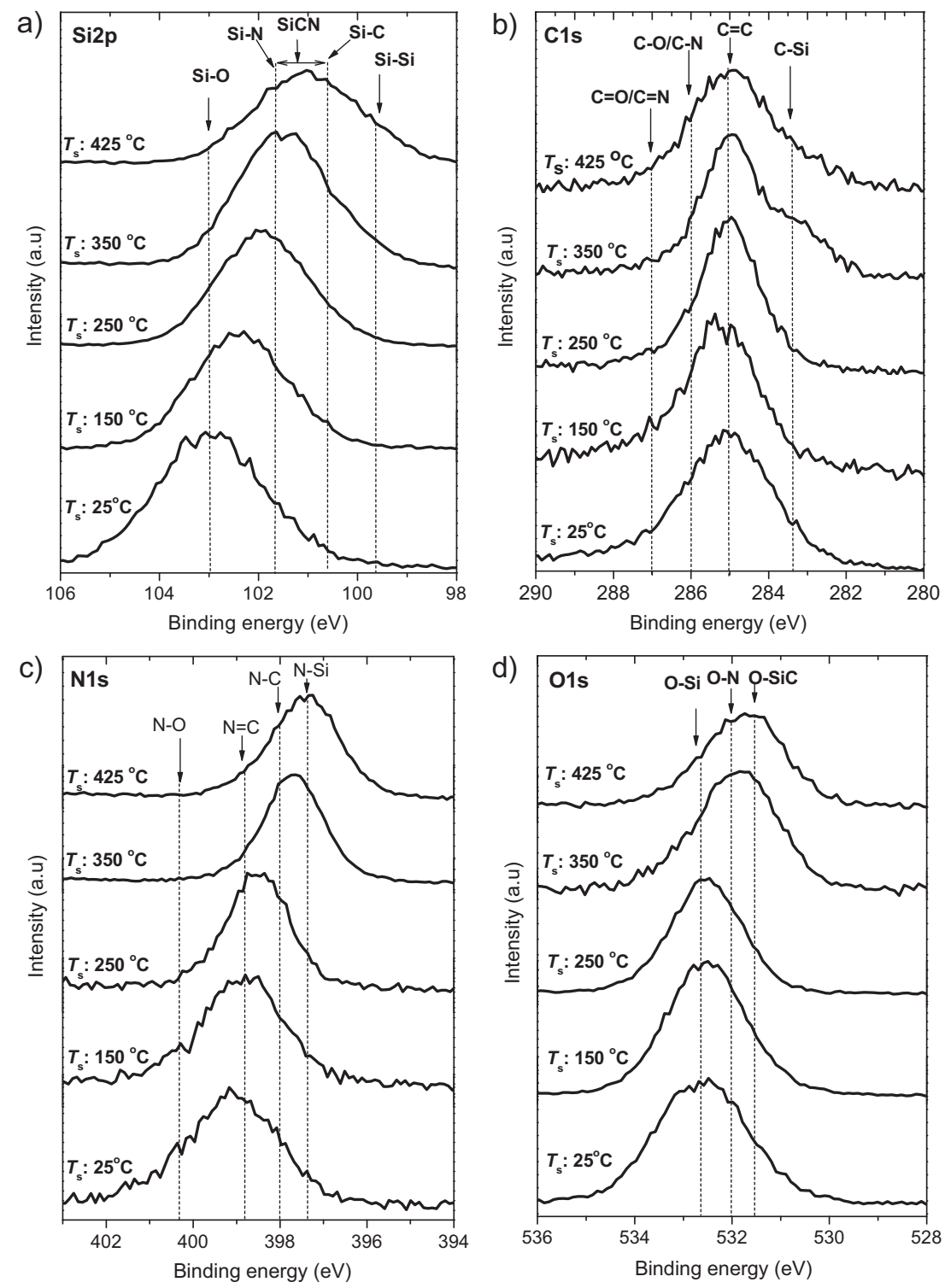

Figure 4. High resolution core level XPS spectra of a-SiCN:H films deposited a function of $T_{\mathrm{s}}$; (a) Si 2p, (b) C 1s, (c) N 1s and (d) O 15 . 

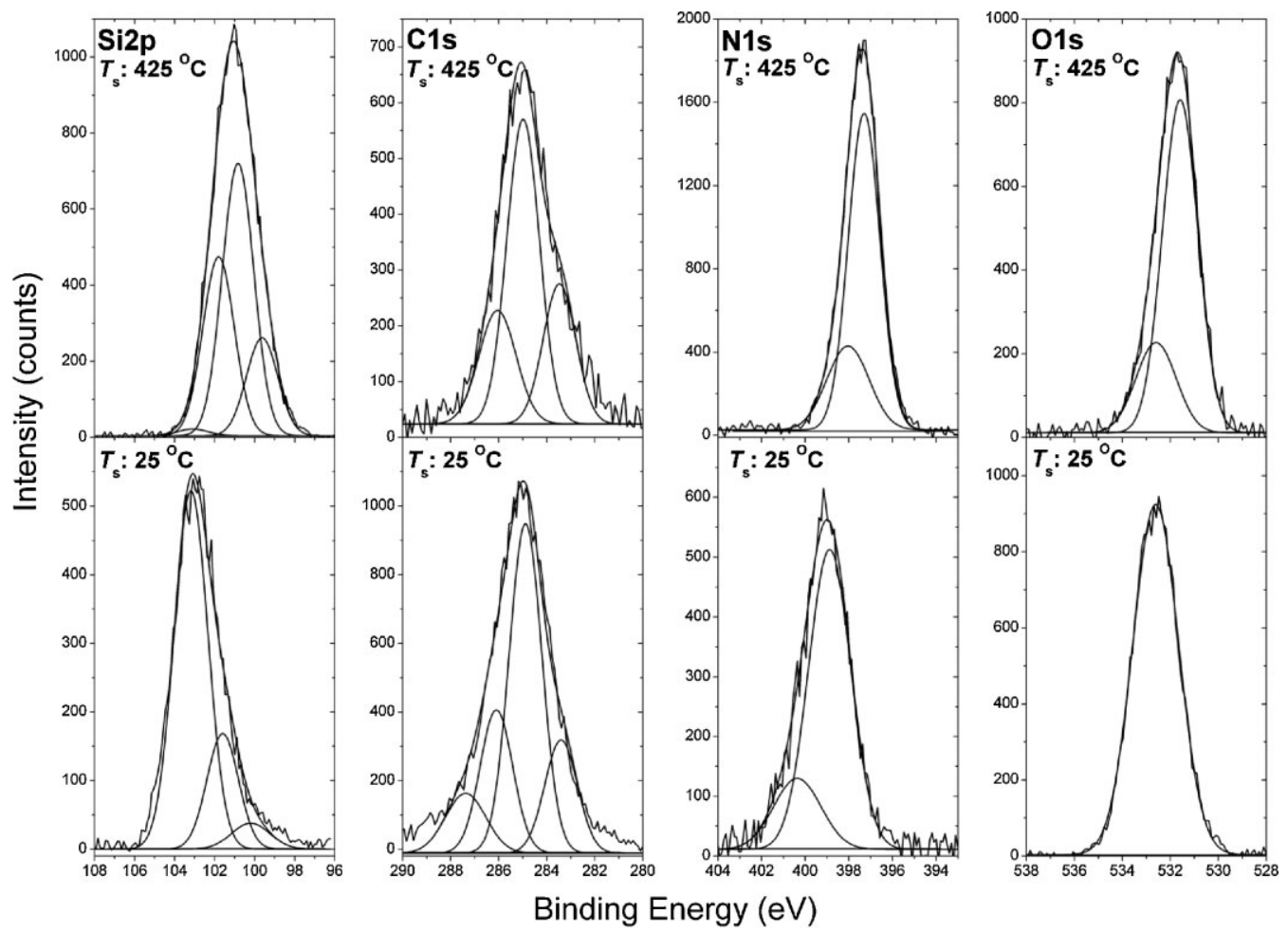

Figure 5. Deconvolution of Si 2p, C 1s, N 1s and O 1s spectra of a-SiCN:H films synthesized at $T_{\mathrm{s}}$ of 25 and $425^{\circ} \mathrm{C}$.

possibility of nitrogen reacting at the Si sites that could be formed due to the thermally induced ethyl group detachment from $\mathrm{SiEt}_{3}$ radical. The above statement is validated by the appearance of $\mathrm{Si}-\mathrm{Si}$ and $\mathrm{Si}-\mathrm{N}$ from Si $2 \mathrm{p}$ core level spectra. From the $\mathrm{O} 1 \mathrm{~s}$ spectra (Figure $4 \mathrm{~d}$ ) it can be seen that at $T_{\mathrm{s}} \leq 250^{\circ} \mathrm{C}$, oxygen was predominately bonded to $\mathrm{Si}$ and at $T_{\mathrm{s}}>250^{\circ} \mathrm{C}$ additional contributions from $\mathrm{O}-\mathrm{N}$ and $\mathrm{O}-\mathrm{SiC}$ could be noticed. Peak broadening observed in Si 2p, C 1s, N $1 \mathrm{~s}$ and $\mathrm{O} 1 \mathrm{~s}$ core levels for the films deposited at $T_{\mathrm{s}} \geq 350^{\circ} \mathrm{C}$ could be attributed to the presence of several complex bonds in a-SiCN films as reported previously by several authors. ${ }^{[39-42]}$

Quantitative information was obtained by deconvoluting the Si 2p, C 1s, N 1s, and O 1s core level spectral bands. Representative deconvoluted spectral features for the core levels for the films deposited at 25 and $425^{\circ} \mathrm{C}$ are depicted in Figure 6. The area under the curve for the individual component contributing to the collective core level elemental spectra is summarized in Table 2. For the films deposited at $25^{\circ} \mathrm{C}$, Si $2 \mathrm{p}$ depicts strong contribution from $\mathrm{Si}-\mathrm{O}(\sim 80.2 \%) \mathrm{Si}-\mathrm{N}(8.0 \%)$ and $\mathrm{Si}-\mathrm{C}(11.8 \%)$ bonds, with the presence of small amounts of $\mathrm{N}-\mathrm{C}$ and $\mathrm{N}-\mathrm{O}$ as observed from the $\mathrm{C}$ 1s and $\mathrm{N} 1 \mathrm{~s}$ spectra, respectively. With a gradual increase in $T_{\mathrm{s}}$, a decrease in $\mathrm{Si}-\mathrm{O}$ contribution and an increase in $\mathrm{Si}-\mathrm{C}$ and $\mathrm{Si}-\mathrm{N}$ bonds were observed. At $T_{\mathrm{s}}=425^{\circ} \mathrm{C}, 47.3 \%$ of $\mathrm{Si}-\mathrm{C}, 40.4 \%$ of $\mathrm{Si}-\mathrm{N}$, and $10.5 \%$ of $\mathrm{Si}-\mathrm{Si}$ bond contributions were calculated from area under the curve. Simultaneously from $\mathrm{N}$ 1s spectral analyses, an increase in the $\mathrm{N}-\mathrm{Si}$ bonds, with a gradual decrease in $\mathrm{N}-\mathrm{C}$ bonds was noticed, indicative of $\mathrm{N}-\mathrm{Si}$ bond formation, which could be attributed to two simultaneous reactions; (i) evolution of ethyl groups (that were bonded to Si) and (ii) nitrogen atoms (from the plasma) reacting with $\mathrm{Si}$ resulting in $\mathrm{Si}-\mathrm{N}$ bonds. The above statements are also supported by the concurrent increase in the $\mathrm{Si}-\mathrm{Si}$ bonds representing enhanced surface cross-linking reactions via elimination of organic moieties as $T_{\mathrm{S}}$ increases. At $T_{\mathrm{S}}$ of
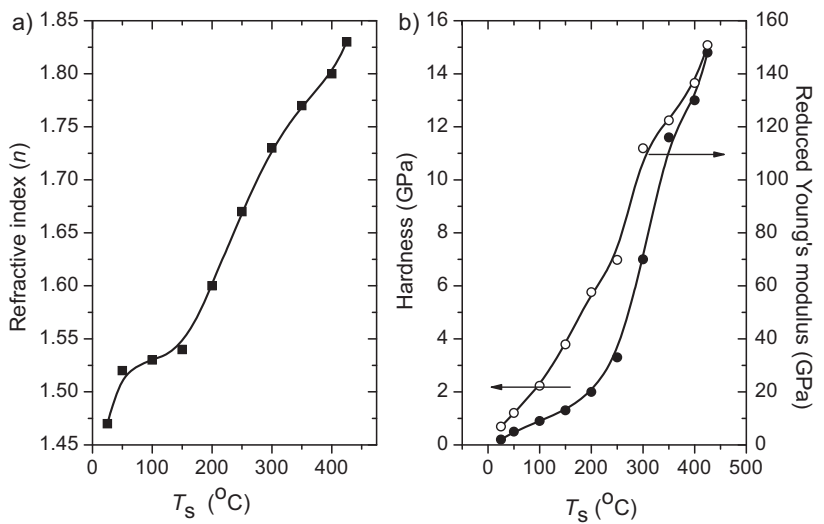

Figure 6. (a) Change in refractive index $(n)$ as function of substrate temperature (b) $H$ and $E_{\mathrm{r}}$ as the function of $T_{\mathrm{s}}$. 
Table 2. Peak position and deconvoluted area of $\mathrm{C} 1 \mathrm{~s}$, Si $2 p$ and $\mathrm{N}$ is peaks from a-SiCN:H films.

\begin{tabular}{|c|c|c|c|c|c|c|c|c|c|c|c|}
\hline \multirow[t]{3}{*}{$T_{\mathrm{s}}\left({ }^{\circ} \mathrm{C}\right)$} & \multicolumn{4}{|c|}{ Si 2p peak $(e V)$} & \multicolumn{4}{|c|}{ C 1s peak $(\mathrm{eV})$} & \multicolumn{3}{|c|}{$\mathbf{N}$ 1s peak $(\mathrm{eV})$} \\
\hline & $\mathrm{Si}-\mathbf{O}$ & $\mathrm{Si}-\mathrm{C}$ & $\mathbf{S i}-\mathbf{N}$ & $\mathbf{S i}-\mathbf{S i}$ & $\mathrm{C}-\mathrm{Si}$ & $\mathrm{C}-\mathrm{C}$ & $\mathrm{C}-\mathrm{N} / \mathrm{C}-\mathrm{O}$ & $\mathbf{C}=\mathbf{N} / \mathbf{C}=\mathbf{O}$ & $\mathbf{N}-\mathbf{S i}$ & $\mathbf{N}-\mathbf{C} / \mathbf{N}=\mathbf{C}$ & $\mathbf{N}-\mathbf{O}$ \\
\hline & 103.0 & 100.4 & 101.7 & 99.9 & 283.3 & 285.0 & 286.0 & 287.0 & 397.3 & 398-399.2 & 400.3 \\
\hline 25 & 80.2 & 11.8 & 8.0 & - & 19.5 & 50.9 & 16.6 & 13.0 & - & 79.1 & 20.9 \\
\hline 150 & 40.4 & 50.2 & 9.4 & - & 8.6 & 55.0 & 36.4 & - & - & 86.5 & 13.5 \\
\hline 250 & 10.5 & 46.4 & 38.4 & 4.7 & 10.4 & 68.9 & 20.7 & - & 8.3 & 84.8 & 6.9 \\
\hline 350 & 6.5 & 21.9 & 65.5 & 6.1 & 27.4 & 53.7 & 18.9 & - & 51.6 & 41.1 & 7.3 \\
\hline 425 & 1.8 & 47.3 & 40.4 & 10.5 & 24.4 & 53.2 & 22.4 & - & 73.9 & 26.1 & - \\
\hline
\end{tabular}

$425^{\circ} \mathrm{C}, 73.9 \%$ of $\mathrm{N}-\mathrm{Si}$ and $26.1 \%$ of $\mathrm{N}-\mathrm{C}$ bond formation were observed from $\mathrm{N}$ 1s spectra deconvolution. A significant increase in the intensity of the Si $2 \mathrm{p}$ and $\mathrm{N}$ 1s peaks, with a simultaneous decrease in the $\mathrm{C} 1 \mathrm{~s}$ and $\mathrm{O} 1 \mathrm{~s}$ peak intensities as a function of increased $T_{\mathrm{s}}$ supported the formation of a $\mathrm{Si}-\mathrm{N}$ rich a-SiCN:H network consisting of $\mathrm{Si}-\mathrm{C}$ bonds. These results are also in agreement with the observations made by FTIR analysis.

Index of refraction $(n)$ and the thickness of the films were determined using spectroscopic ellipsometry. Figure $5 \mathrm{a}$ depicts $n$ as a function of $T_{\mathrm{s}}$. Films deposited at $T_{\mathrm{s}}<150^{\circ} \mathrm{C}$ showed $n$ lower than 1.54, while with an increase in $T_{\mathrm{s}}$ above $150^{\circ} \mathrm{C}$ a gradual increase in $n$ could be observed. At $T_{\mathrm{s}}=425^{\circ} \mathrm{C}, n$ of 1.84 was observed. Figure $6 \mathrm{~b}$ shows $H$ and $E_{\mathrm{r}}$ determined using nanoindentation as a function of $T_{\mathrm{s}}$. Films deposited at RT depict low $H$ and $E_{\mathrm{r}}$ of 0.2 and $6.9 \mathrm{GPa}$, respectively, while with an increase in $T_{\mathrm{s}}$ a gradual increase in $H$ and $E_{\mathrm{r}}$ could be noticed and at $T_{\mathrm{s}}=425^{\circ} \mathrm{C}, \mathrm{H}$ of $14.8 \mathrm{GPa}$ and $E_{\mathrm{r}}$ of $150.8 \mathrm{GPa}$ were observed.

The $n, H$, and $E_{\mathrm{r}}$ values observed for the a-SiCN:H films that were deposited at $T_{\mathrm{s}}$ above $300^{\circ} \mathrm{C}$ are comparable to the films deposited with vacuum based processes. ${ }^{[1,36,39]}$ In accordance with the FTIR and XPS results presented earlier the increase in $n$ can be attributed to the formation of ceramic like a-SiCN phase which possess higher nitrogen content than the films that were deposited at lower temperatures. Another reason for the increase in $n$ could be due to the increase in the film density as the function of substrate temperature. A similar increase in $n$ for the $\mathrm{a}-\mathrm{SiN}_{x}, \mathrm{a}-\mathrm{SiC}: \mathrm{H}$, and $\mathrm{a}-\mathrm{SiCN}: \mathrm{H}$ films were reported as the function of ion-bombardment or $T_{\mathrm{s}}$ for the films deposited using vacuum based plasma process such as sputtering and PECVD. ${ }^{[29,39,43]}$ The increase in $H$ and $E_{\mathrm{r}}$ can also be attributed to the increase in the density of the films, with a concurrent change occurring in the elemental concentration and the film microstructure as observed from the FTIR and XPS analysis (which depicts the change in film structure from organic to ceramic structure as the function of $T_{\mathrm{s}}$ ).
Figure 7 depicts thickness based growth rate of a-SiCN:H films as the function of $1000 / T_{\mathrm{s}}\left(\mathrm{K}^{-1}\right)$. The change in the film thickness as the function of $T_{\mathrm{S}}$ is presented in the inset of Figure 7. With an increases in $T_{\mathrm{s}}$ from $25^{\circ} \mathrm{C}$, a gradual decrease in film thickness from 823 to $120 \mathrm{~nm}$ (at $250^{\circ} \mathrm{C}$ ) was observed, while an increase in $T_{\mathrm{s}}$ above $250^{\circ} \mathrm{C}$ showed an increase in the film thickness to $200 \mathrm{~nm}$ at $425^{\circ} \mathrm{C}$. Growth rates plotted as $1000 / T_{\mathrm{S}}$ depict positive and negative slopes between $25-250^{\circ} \mathrm{C}$ and $250-425^{\circ} \mathrm{C}$, respectively. Decreasing slope (decrease in the film thickness) can be attributed to the thermally activated desorption of organic moieties $\left(\mathrm{CH}_{n}\right)$ from the adsorbed species on the substrate and enhanced surface diffusion of the adsorbed molecules leading to smooth denser films, which is supported by the increasing trend in $n, H$, and $E_{\mathrm{r}}$ values measured for the films deposited in this regime as explained earlier. ${ }^{[43]}$ With an increase in $T_{\mathrm{s}}$ above $250^{\circ} \mathrm{C}$ the combination of thermally induced desorption of organic moieties at the substrate surface, improved chemical

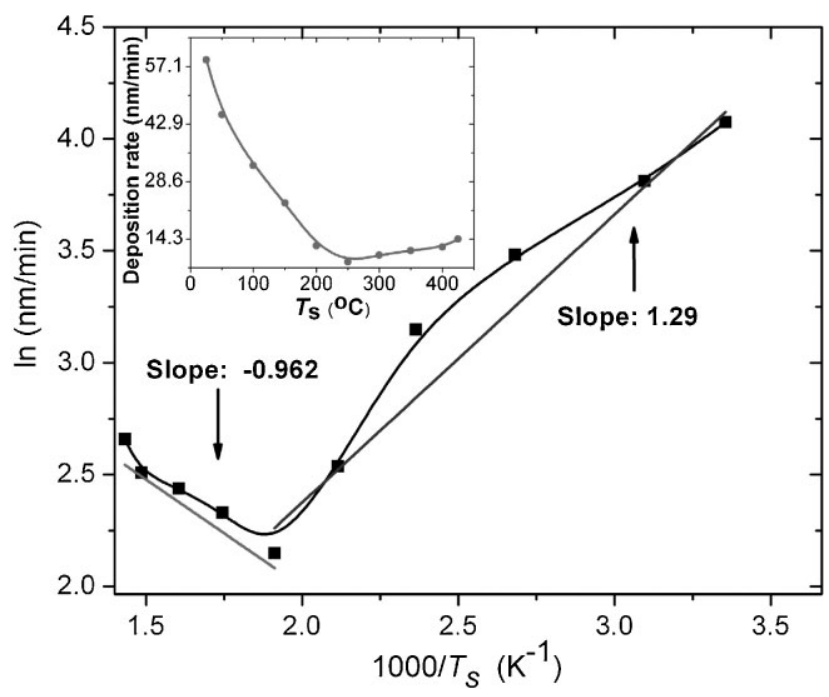

Figure 7. Deposition rate (logarithmic) as the function of $1000 / T_{\mathrm{s}}$ $\left(\mathrm{K}^{-1}\right)$ and change in film thickness as a function of $T_{\mathrm{s}}$ (inset). 
reactions between the adsorbed species with the growing film, along with higher adatom surface mobility are expected to enhance the formation of more dense, ceramic like films at higher growth rates, which was supported by the experimental observations (such as increase in nitrogen content with decrease in the carbon, and with an increase in $n, H, E_{\mathrm{r}}$, and a decrease in $R_{\mathrm{a}}$ ). Saturation in the growth rates beyond critical $T_{\mathrm{S}}$ is typical for thermally induced CVD process, in our case no such saturation was observed up to $425^{\circ} \mathrm{C} \cdot{ }^{[32]}$

In a typical CVD process the growth rate $(\dot{G})$ can be expressed by the equation $\dot{G}=\left(K_{\mathrm{g}} h_{\mathrm{g}} C_{\mathrm{g}}\right) /\left(K_{\mathrm{g}}+h_{\mathrm{g}}\right) N_{\mathrm{o}}$, where $k_{\mathrm{s}}$ is the reaction rate, $C_{\mathrm{g}}$ is the concentration of reactant flux in the bulk gas, $h_{\mathrm{g}}$ is the mass transfer coefficient, and $N_{\mathrm{o}}$ is the atomic density of the thin film. ${ }^{[32]} \mathrm{At}$ low $T_{\mathrm{s}}$, reaction rate $\left(k_{\mathrm{s}}\right)$ controls the film growth (surface reaction controlled), on the other hand at high $T_{\mathrm{s}}$ masstransfer $\left(h_{\mathrm{g}}\right)$ controls the film growth. Gas phase diffusion of radicals depends on the pressure and temperature according to the relation $\sim T^{3 / 2} / P{ }^{[32]}$ In this study, since pressure was maintained a constant during the deposition, an increase in $T_{\mathrm{s}}$ will favor more gas-phase diffusion of precursor molecule/radicals towards the substrate. Also, as a function of $T_{\mathrm{s}}$ the surface reaction rate increased in accordance with Arrhenius behavior that is explained by the relation $k_{\mathrm{s}}=\left[\exp \left(-E / R T_{\mathrm{s}}\right)\right]$, where $E$ is the activation energy and $R$ is gas constant. ${ }^{[4]}$ This is indicative of an enhanced reaction between the adsorbed species at higher temperatures, supported by the increase in nitrogen and decrease in carbon content of a-SiCN:H films deposited at high $T_{\mathrm{s}}$ (result of plasma activated nitrogen species reaction with $\mathrm{SiEt}_{3}$ radicals on the substrate). These two processes (enhanced reactivity and higher radical diffusion) are accounted for the increase in film thickness for $T_{\mathrm{s}}$ ranging from 250 to $425^{\circ} \mathrm{C}$. Jumping frequency $(\Gamma)$ of the adsorbed molecular species is directly proportional to $\alpha\left[\exp \left(-E_{\text {diff }} /\right.\right.$ $\left.R T_{\mathrm{s}}\right)$ ]. With an increase in $T_{\mathrm{s}}$ the jumping frequency increases, allowing higher root mean square displacement of the adsorbed species on the surface, hence leading to an energetically favorable position to form a stable film. ${ }^{[32]}$ Also a slight decrease in the surface energy with increase in $T_{\mathrm{S}}$ assists the surface diffusion process and leads to a smoother film formation. As depicted in Figure 7 the negative slope indicates a typical thermal CVD process in this regime, but occurring at lower temperatures than typical thermal CVD processes.

Based on above arguments, it can be surmised that at low temperatures, the film growth is surface reaction controlled, whereas at high temperature the growth mechanism is controlled by bulk and surface diffusion with enhanced chemical reactivity. Thus it can stated that APPECVD processes are similar to plasma polymerization at low temperatures, where the monomer molecules are activated by plasma and the activated molecules react/ adsorb with or on the substrate depending on the surface chemistry or the surface energy, while at higher substrate temperatures the process is similar to remote plasma activated CVD, at atmospheric pressure.

To understand the excited nitrogen species present in the afterglow region of the plasma, OES analyses were carried out. OES measurements were performed in $\mathrm{He}$ and $\mathrm{He}+\mathrm{N}_{2}$ plasmas with the emission spectra depicted in Figure 8. OES spectrum of a He plasma (Figure 8a) showed the characteristic emission peaks of He at $587 \mathrm{~nm}\left(2^{3} \mathrm{P} \rightarrow 3^{3} \mathrm{D}\right)$, $667 \mathrm{~nm}\left(2^{1} \mathrm{P} \rightarrow 3^{1} \mathrm{D}\right)$, and $706.5 \mathrm{~nm} \cdot{ }^{[45,46]}$ Figure $8 \mathrm{~b}$ depicts the emission spectrum of He plasma diluted with $0.5 \mathrm{lpm}$ of $\mathrm{N}_{2}$. The characteristic He peak observed at $706 \mathrm{~nm}$ in pure He plasma diminished while typical characteristic peaks that corresponded to $\mathrm{N}, \mathrm{N}^{+}, \mathrm{N}_{2}$, and $\mathrm{N}_{2}^{+}$were observed in the spectrum due the addition of nitrogen. It was also observed that the emission spectrum was dominated by the $\mathrm{N}_{2}^{+}$ bands whose peak positions are at 337.1, 353.6, 357.7, 371.0, $375.5,380.5$, and $394.3 \mathrm{~nm}$. Weak $\mathrm{N}_{2}^{+}$transitions due to Penning ionization of $\mathrm{N}_{2}$ with $\mathrm{He}$ gas molecules were observed at 391.4 and $427.7 \mathrm{~nm}$ (see Figure 8a) were also observed. ${ }^{[47,48]}$ Transitions associated with atomic nitrogen were detected, which are known to be weak compared to the radiative transitions of molecular nitrogen. ${ }^{[4]}$ In the plasma, electron bombardment with molecular nitrogen can cause formation of $\mathrm{N}_{2}^{+}$and $\mathrm{N}$, while the excited $\mathrm{He}$ interaction with $\mathrm{N}_{2}$ (present in the ambient) via Penning ionization to form $\mathrm{N}_{2}^{+}$ions is clearly present in Figure $8 \mathrm{a}$. The above mentioned plasma reactions can be represented by the following equations; ${ }^{[49]}$

$$
\begin{aligned}
& \mathrm{N}_{2}+\mathrm{e}^{-} \rightarrow \mathrm{N}_{2}^{+}+2 \mathrm{e}^{-} \text {(ionization) } \\
& \mathrm{N}_{2}+\mathrm{e}^{-} \rightarrow 2 \dot{\mathrm{N}}+\mathrm{e}^{-} \text {(dissociation) } \\
& \mathrm{He}^{*}+\mathrm{N}_{2} \rightarrow \mathrm{He}+\mathrm{N}_{2}^{+}+\mathrm{e}^{-} \text {(penning ionization) }
\end{aligned}
$$

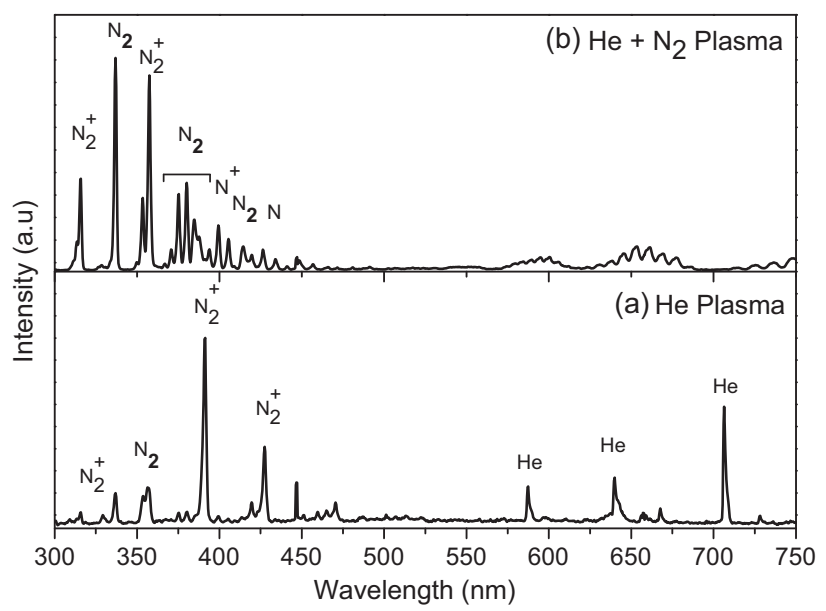

Figure 8. OES spectra (a) $\mathrm{He}$ and (b) $\mathrm{He}+\mathrm{N}_{2}$ plasma at $120 \mathrm{~W}$ of plasma power. 
From the observed OES results and film properties, a possible chemical route active in the AP-PECVD process using nitrogen and TES can be suggested. The OES spectra collected in the afterglow region (where the precursor vapor is injected) of the plasma depicts the presence of activated $\mathrm{N}_{2}^{+}, \mathrm{N}^{+}$, and $\mathrm{N}$ species. These nitrogen species can react with the precursor molecule in accordance with Equation (3-5) leading to formation of $\mathrm{Et}_{3} \dot{\mathrm{S}}_{1}$ radicals:

$$
\begin{aligned}
& \mathrm{N}_{2}^{+}+\mathrm{HSiEt}_{3} \rightarrow \mathrm{Et}_{3} \dot{\mathrm{S}}_{1}+\mathrm{N}_{2}+\mathrm{H}^{+} \\
& \mathrm{N}^{+}+\mathrm{HSiEt}_{3} \rightarrow \mathrm{Et}_{3} \dot{\mathrm{S}}_{1}+\mathrm{N}+\mathrm{H}^{+} \\
& \mathrm{N}+\mathrm{HSiEt}_{3} \rightarrow \mathrm{Et}_{3} \dot{\mathrm{S}}_{1}+\mathrm{NH}
\end{aligned}
$$

As proposed by Wrobel et al., ${ }^{[36]}$ the silyl group formed in above equations may react with $\mathrm{HSiEt}_{3}$ in the gas phase or with the growing film, forming a radical on the carbon atoms, as depicted in below:

$$
\begin{aligned}
& \mathrm{Et}_{3} \dot{\mathrm{S}}_{1}+\mathrm{CH}_{3} \mathrm{CH}_{2} \mathrm{Si}(\mathrm{Et})_{2} \mathrm{H} \\
& \rightarrow(\mathrm{Et})_{3} \mathrm{Si}-\mathrm{CH}_{2}-\dot{\mathrm{C}} \mathrm{H}_{2} \text { (or) }(\mathrm{Et})_{3} \mathrm{Si}-\dot{\mathrm{C}} \mathrm{H}-\mathrm{CH}_{3}+\mathrm{HSiEt}_{3}
\end{aligned}
$$

The radical formed in the above reaction may undergo thermally induced decomposition at high $T_{\mathrm{s}}$ by the elimination of ethylene groups as by-product, as described below: ${ }^{[36]}$

$$
\begin{aligned}
& \equiv \mathrm{Si}-\mathrm{CH}_{2}-\dot{\mathrm{C}} \mathrm{H}_{2} \underset{\rightarrow}{\rightarrow} \equiv \mathrm{Si}-\mathrm{H}+\mathrm{C}_{2} \mathrm{H}_{4} \\
& \equiv \mathrm{Si}-\mathrm{CH}_{2}-\mathrm{CH}_{3} \underset{\rightarrow}{\Delta} \equiv \mathrm{Si}-\mathrm{H}+\mathrm{C}_{2} \mathrm{H}_{4}
\end{aligned}
$$

The above mentioned reactions help in the removal of organic moieties in the growing film and in our case, this occurs most effectively at $T_{\mathrm{s}} \geq 250^{\circ} \mathrm{C}$ leading to the formation of $\mathrm{Si}-\mathrm{H}_{n}$ as observed from the growth of the corresponding IR band (Figure 3).

The radical structure formed in Equation (7) may react with $\mathrm{Et}_{3} \dot{\mathrm{S}}_{1}$ radical formed in Equation (4), (5), or (6), or may recombine at the growth surface as indicated below:

$$
\mathrm{Et}_{3} \dot{\mathrm{S}}_{1}+\dot{\mathrm{C}} \mathrm{H}_{2}-\mathrm{CH}_{2}-\mathrm{SiEt}_{2} \rightarrow \mathrm{Et}_{3} \mathrm{Si}-\mathrm{CH}_{2}-\mathrm{CH}_{2}-\mathrm{SiEt}_{3}
$$

Similarly, two $\mathrm{Et}_{3} \dot{\mathrm{S}}_{1}$ radical may combine with each other to form a disilane based moiety as shown below:

$$
2\left(\mathrm{Et}_{3} \dot{\mathrm{S}}_{1}\right) \rightarrow \mathrm{Et}_{3} \mathrm{Si}-\mathrm{SiEt}_{3}
$$

At elevated temperatures the above formed group may react with hydrosilyl $\left(\mathrm{Si}-\mathrm{H}_{n}\right)$ groups at the growth surface via thermally induced cross linking reaction to form [-Si-C-] network as proposed by Wrobel et al. ${ }^{[36]}$

The $\mathrm{N}_{2}^{+}, \mathrm{N}^{+}, \mathrm{N}$ species produced in the plasma and the reactive $\mathrm{H}$ (formed as the byproducts from $\mathrm{HSiEt}_{3}$,) can form reactive amino group (NH) (by-product of Equation 6) and other reactive products as depicted below:

$$
\begin{aligned}
& \mathrm{N}_{2}^{+}+\mathrm{H} \rightarrow \mathrm{N}_{2} \mathrm{H}^{+} \\
& \mathrm{N}^{+}+\mathrm{H} \rightarrow \mathrm{NH}^{+}
\end{aligned}
$$

The $\mathrm{NH}$ group and the reactive $\mathrm{N}$ can react with (Et) ${ }_{3} \mathrm{Si}-\mathrm{CH}_{2}-\dot{\mathrm{C}} \mathrm{H}_{2}$ (Equation 7) at the growing surface as shown below: ${ }^{[6]}$

$$
\begin{aligned}
& \mathrm{NH}+(\mathrm{Et})_{3} \mathrm{Si}-\mathrm{CH}_{2}-\dot{\mathrm{C}} \mathrm{H}_{2} \rightarrow(\mathrm{Et})_{3} \mathrm{Si}-\mathrm{NH}-\mathrm{CH}_{2}-\dot{\mathrm{C}} \mathrm{H}_{2} \\
& \mathrm{~N}+\mathrm{Et}_{3} \dot{\mathrm{S}}_{1} \rightarrow \mathrm{Et}_{2} \dot{\mathrm{S}}_{1}-\mathrm{CN}+\mathrm{C}_{2} \mathrm{H}_{4}+\mathrm{H}_{2}
\end{aligned}
$$

The organic moieties that are attached to the product that is formed in the above equation may undergo thermally induced desorption at higher $T_{\mathrm{S}}$ leading to the formation of $\mathrm{Si}-\mathrm{N}$ and $\mathrm{Si}-\mathrm{C}-\mathrm{N}$ networks via crosslinking.

Similarly the hydrosilyl group formed as the product of the radicals shown in Equation (10) and (11) may readily react with $\mathrm{NH}$ as depicted below:

$$
\mathrm{Si}-\mathrm{H}_{n}+\mathrm{NH} \rightarrow \equiv \mathrm{Si}-\mathrm{NH}+\mathrm{H}_{n}
$$

This group may undergo crosslinking reaction with other carbosilane groups leading to the formation of complex a-SiCN:H films. The observed decrease in $\mathrm{Si}-\mathrm{H}_{n}$ intensity and increase in the absorption of $\mathrm{SiC} / \mathrm{Si}-\mathrm{N}$ at $T_{\mathrm{s}} \geq 350^{\circ} \mathrm{C}$ suggest the possibility of the above mentioned reactions. ${ }^{[6]}$

Also $\mathrm{NH}$ group incorporation in the $\mathrm{Et}_{3} \dot{\mathrm{S}}_{1}$ groups can occur at the growth surface as depicted below:

$$
\begin{aligned}
& \mathrm{NH}+\mathrm{Et}_{3} \dot{\mathrm{S}}_{1} \rightarrow\left[\mathrm{Et}_{3} \mathrm{SiNH}\right]^{\bullet} \\
& {\left[\mathrm{Et}_{3} \mathrm{SiNH}\right]^{\bullet}+\mathrm{Et}_{3} \dot{\mathrm{S}}_{1} \rightarrow \mathrm{Et}_{3} \mathrm{Si}-\mathrm{N}(\mathrm{H})-\mathrm{SiEt}_{3}} \\
& \mathrm{Et}_{3} \mathrm{Si}-\mathrm{N}(\mathrm{H})-\mathrm{SiEt}_{3} \rightarrow(\mathrm{Et})_{3} \mathrm{Si}-\mathrm{N}(\mathrm{H})-\mathrm{Si}\left(\mathrm{Et}_{3}\right)_{2}-\mathrm{CH}_{2}-\dot{\mathrm{C}} \mathrm{H}_{2}
\end{aligned}
$$

The products formed in the above equations may undergo thermally activated decomposition at higher $T_{\mathrm{s}}$ to form $\mathrm{Si}-\mathrm{N}$ and $\mathrm{Si}-\mathrm{C}-\mathrm{N}$ based network via elimination of organic moieties and cross-linking reaction as discussed earlier which correlate well with observations made from XPS and FTIR spectroscopic techniques.

From the discussions and the experimental observations at low $T_{\mathrm{s}}$, the activated $\mathrm{HSiEt}_{3}$ molecules and the $\mathrm{NH}$ species 
(formed as a byproduct of the gas-phase reactions) become adsorbed on the substrate with minimum reactivity. As the $T_{\mathrm{s}}$ increases to $250^{\circ} \mathrm{C}$ the 1,1-diethyl-2-methysilene molecule desorbs the ethyl and ethylene groups leading to the formation of $\mathrm{Si}-\mathrm{H}_{n}$ as evident from the FTIR analysis. Reaction between the $\mathrm{Si}-\mathrm{H}_{n}$ and the $\mathrm{NH}$ becomes more probable at $T_{\mathrm{S}}$ above $350^{\circ} \mathrm{C}$ leading to the formation of complex a-SiCN:H ceramic like films.

\section{Conclusion}

a-SiCN:H films were deposited on c-Si using AP-PECVD with TES and nitrogen. The substrate temperature plays a crucial role in controlling the structure and the chemical composition of a-SiCN:H films. The increase in $T_{\mathrm{s}}$ eliminates the organic moieties and incorporates more nitrogen in the film leading to the formation of ceramic like film structure. Film growth rate showed strong dependence on the $T_{\mathrm{s}}$. Between 25 and $250^{\circ} \mathrm{C}$ the film thickness decreased with an increase in $T_{\mathrm{s}}$, which showed the film growth mechanism was surface reaction controlled, while between 250 and $425^{\circ} \mathrm{C}$ the film thickness increased which indicated that film growth mechanism is mass-transport controlled. No film formation was observed without $\mathrm{N}_{2}$ addition to the plasma gas (He), which indicated AP-PECVD was a radical initiated process. From the depicted possible chemical reactions it can be concluded that the nitrogen reactive species in the after-glow region of the plasma initiated the fragmentation of the $\mathrm{HSiEt}_{3}$, which on subsequent reaction in the gasphase and on the substrate with $\mathrm{NH}$ species leads to the formation of a-SiCN:H films whose structure and properties strongly depend on the $T_{\mathrm{s}}$.

Acknowledgements: This material is based on research sponsored by the Department of Energy grant DE-FG36-08GO88160. The views and conclusions contained herein are those of the authors and should not be interpreted as necessarily representing the official policies or endorsements, either expressed or implied of the Department of Energy or the U.S. Government. Authors would like to thank Drs. D. L. Schulz, S. Elangovan, and G. R. S. Iyer for their constructive suggestions and comments. Help from Ms. H. Doktor and Mr. J. Risan (MCAL) and Mr. S. Payne (Electron Microscopy Center, NDSU) for their assistance in FTIR, NI, and SEM characterizations, respectively, are greatly appreciated. XPS measurements were carried out in the Characterization Facility, University of Minnesota, as part of the NSF-funded Materials Research Facilities Network and funded by the National Science Foundation (NSF) through the University of Minnesota Materials Research Science and Engineering Center (MRSEC) Materials Research Facilities Network (MRFN) supplemental funding award. The authors would like to gratefully acknowledge Dr. Bing Luo, Dr. Timothy Lodge, Dr. John Nelson, Alice Ressler, and Sharon Emde for this opportunity.

Received: February 17, 2011; Revised: June 27, 2011; Accepted: July 18, 2011; DOI: 10.1002/ppap.201100035
Keywords: atmospheric pressure glow discharge; atmospheric pressure plasma enhanced chemical vapor deposition (APPECVD); plasma-precursor interaction and growth kinetics; remote plasma

[1] S. Guruvenket, M. Azzi, D. Li, J. A. Szpunar, L. Martinu, J. E. Klemberg-Sapieha, Surf. Coat. Technol. 2010, 204, 3358.

[2] B. Sopori, J. Electron. Mater. 2005, 34, 564.

[3] C. C. Chiang, M. C. Chen, C. C. Ko, S. M. Jang, C. H. Yu, M. S. Liang, Jpn. J Appl. Phys 1 2003, 42, 5246.

[4] D. Li, S. Guruvenket, M. Azzi, J. A. Szpunar, J. E. KlembergSapieha, L. Martinu, Surf. Coat. Technol. 2010, 204, 1616.

[5] N. Cherault, G. Carlotti, N. Casanova, P. Gergaud, C. Goldberg, O. Thomas, M. Verdier, Microelectron. Eng. 2005, 82, 368.

[6] A. M. Wrobel, I. Blaszczyk-Lezak, A. Walkiewicz-Pietrzykowska, J. Appl. Polym. Sci. 2007, 105, 122.

[7] A. M. Wrobel, I. Blaszczyk-Lezak, A. Walkiewicz-Pietrzykowska, T. Aoki, J. Kulpinskic, J. Electrochem. Soc. 2008, 155, K66.

[8] A. M. Wrobel, I. Blaszczyk-Lezak, A. Walkiewicz-Pietrzykowska, D. M. Bielinski, T. Aoki, Y. Hatanaka, J. Electrochem. Soc. 2004, 151, C723.

[9] A. M. Wrobel, A. Walkiewicz-Pietrzykowska, I. BlaszczykLezak, Appl. Organomet. Chem. 2010, 24, 201.

[10] I. Blaszczyk-Lezak, A. M. Wrobel, D. M. Bielinski, Diamond Relat. Mater. 2006, 15, 1650.

[11] E. Gonzalez, M. D. Barankin, P. C. Guschl, R. F. Hicks, Langmuir 2008, 24, 12636 .

[12] F. Fanelli, R. d'Agostino, F. Fracassi, Plasma Process. Polym. 2007, 4, 797.

[13] F. Fanelli, F. Fracassi, R. d'Agostino, Surf. Coat. Technol. 2010, 204, 1779.

[14] L. Bárdos, H. Baránková, Thin Solid Films 2010, 518, 6705.

[15] V. Raballand, J. Benedikt, S. Hoffmann, M. Zimmermann, A. von Keudell, J. Appl. Phys. 2009, 105, 083304.

[16] V. Raballand, J. Benedikt, A. von Keudell, Appl. Phys. Lett. 2008, 92, 091502.

[17] V. Hopfe, D. W. Sheel, Plasma Process. Polym. 2007, 4, 253.

[18] V. Hopfe, D. W. Sheel, IEE Trans. Plasma Sci. 2007, 35, 204.

[19] V. Hopfe, R. Spitzl, I. Dani, G. Maeder, L. Roch, D. Rogler, B. Leupolt, B. Schoeneich, Chem. Vapor. Depos. 2005, 11, 497.

[20] G. R. Nowling, S. E. Babayan, V. Jankovic, R. F. Hicks, Plasma Sources Sci. 2002, 11, 97.

[21] G. R. Nowling, S. E. Babayan, X. Yang, M. Moravej, R. Agarwal, R. F. Hicks, Plasma Sources Sci. 2004, 13, 156.

[22] A. M. Ladwig, R. D. Koch, E. G. Wenski, R. F. Hicks, Diamond Relat. Mater. 2009, 18, 1129.

[23] K. W. Johnson, S. Jha, C. Braun, K. Anderson, B. Halverson, K. Pokhodnya, S. Guruvenket, R. A. Sailer, D. L. Schulz, 52nd Annual Technical Conference Proceedings, Society of Vacuum Coaters, 2009, 327.

[24] K. W. Johnson, S. Guruvenket, S. Jha, B. Halverson, C. Olson, R. A. Sailer, D. L. Schulz, 34th IEEE Photovoltaic Specialists Conference, 2009, 001806.

[25] R. A. Sailer, A. Wagner, C. Schmit, N. Klaverkamp, D. L. Schulz, Surf. Coat. Technol. 2008, 203, 835.

[26] M. D. Barankin, E. Gonzalez, A. M. Ladwig, R. F. Hicks, Sol. Energy Mater. Sol. Cells 2007, 91, 924.

[27] M. Moravej, R. F. Hicks, Chem. Vapor. Depos. 2005, 11, 469.

[28] W. C. Oliver, G. M. Pharr, J. Mater. Res. 1992, 7, 1564.

[29] S. Guruvenket, J. Ghatak, P. V. Satyam, G. M. Rao, Thin Solid Films 2005, 478, 256. 
[30] A. Amassian, R. Vernhes, J. E. Klemberg-Sapieha, P. Desjardins, L. Martinu, Thin Solid Films 2004, 469-70, 47.

[31] Z. L. Fang, Surf. Coat. Technol. 2008, 202, 4198.

[32] M. Ohring, Materials Science of Thin Films - Deposition and Structure, 2nd edition, Academic Press, New York, USA, 2002.

[33] Y. Awad, M. A. El Khakani, C. Aktik, J. Mouine, N. Camire, M. Lessard, M. Scarlete, H. A. Al-Abadleh, R. Smirani, Surf. Coat. Technol. 2009, 204, 539.

[34] D. S. Kim, Y. H. Lee, Thin Solid Films 1996, 283, 109.

[35] R. Di Mundo, M. Ricci, R. d'Agostino, F. Fracassi, F. Palumbo, Plasma Process. Polym. 2007, 4, S21.

[36] A. M. Wrobel, A. Walkiewicz-Pietrzykowska, M. Ahola, I. J. Vayrynen, F. J. Ferrer-Fernandez, A. R. Gonzalez-Elipe, Chem. Vapor. Depos. 2009, 15, 39.

[37] E. Gat, M. A. Elkhakani, M. Chaker, A. Jean, S. Boily, H. Pepin, J. C. Kieffer, J. Durand, B. Cros, F. Rousseaux, S. Gujrathi, J. Mater. Res. 1992, 7, 2478.

[38] F. J. Gomez, P. Prieto, E. Elizalde, J. Piqueras, Appl. Phys. Lett. $1996,69,773$.

[39] P. Jedrzejowski, J. Cizek, A. Amassian, J. E. Klemberg-Sapieha, J. Vlcek, L. Martinu, Thin Solid Films 2004, 447, 201.
[40] Y. Awad, M. A. El Khakani, M. Scarlete, C. Aktik, R. Smirani, N. Camire, M. Lessard, J. Mouine, J. Appl. Phys. 2010, 107, 033517.

[41] X. M. He, T. N. Taylor, R. S. Lillard, K. C. Walter, M. Nastasi, J. Phys.:Condens. Matter 2000, 12, 8937.

[42] Y. Awad, M. A. El Khakani, D. Brassard, R. Smirani, N. Camire, M. Lessard, C. Aktik, M. Scarlete, J. Mouine, Thin Solid Films 2010, 518, 2738.

[43] J. Niemann, W. Bauhofer, Thin Solid Films 1999, 352, 249.

[44] J. W. Sun, Y. F. Zhang, D. Y. He, Diamond Relat. Mater. 2000, 9 , 1668.

[45] J. L. Walsh, J. J. Shi, M. G. Kong, Appl. Phys. Lett. 2006, 89, 171501.

[46] V. Leveille, S. Coulombe, Plasma Sources Sci. 2005, 14, 467.

[47] W. C. Zhu, Q. Li, X. M. Zhu, Y. K. Pu, J. Phys. D Appl. Phys. 2009, 42, 202002.

[48] A. J. Wagner, D. H. Fairbrother, F. Reniers, Plasma Polym. 2003, 8, 119.

[49] A. M. Wrobel, I. Blaszczyk, A. Walkiewicz-Pietrzykowska, A. Tracz, J. E. Klembrg-Sapieha, T. Aoki, Y. Hatanaka, J. Mater. Chem. 2003, 13, 731. 